\title{
Relationship of team learning and organizational culture with knowledge management in second grade high school teachers in Saveh city
}

\author{
Mahboobeh Farshad \\ Department of educational management, college of human science, Saveh Branch \\ Islamic Azad University, Saveh, Iran \\ Email: ttrust617@gmail.com \\ Dr. Gholamreza Azizi (Corresponding author) \\ Department of educational management, college of human science, Saveh Branch \\ Islamic Azad University, Saveh, Iran \\ Email: ghrezaazizi@ymail.com
}

Doi:10.5296/ jsr.v6i2.8577 URL: http://dx.doi.org/10.5296/ jsr.v6i2.8577

\begin{abstract}
The purpose of the present research was to study the relationship of team learning and organizational culture with knowledge management in teachers of the second course of high schools in Saveh city in 2014. The method used in this research was practical in terms of objectives and correlational-descriptive in terms of data collection method. The statistical population consisted of 160 individuals including all the second grade high school teachers in Saveh city. In this regard, 113 individuals (65 males and 4 females) were considered as a sample size using the Cochran formula and the Stratified random sampling method. In order to collect the data, three standard questionnaires of team learning of Breso et al. (2008), knowledge management of Fong \& Choi (2009), and organizational culture of Denison (2000) were employed. In order to assess the reliability of the questionnaires, the Cronbach's alpha method was used and the related coefficients were $0.84,0.82$, and 0.94 respectively for each of the questionnaires. Moreover, in order to assess the validity, the content validity was used, and the questionnaires were confirmed by the relevant experts. The analysis of the obtained data was performed through SPSS software in the two sections of descriptive and inferential (Pearson correlation and multivariable regression). The research findings indicated that there is a significant relationship between team learning and organizational culture, and knowledge management. The findings also demonstrated that the variables of team learning and organizational culture can predict the variable of knowledge management.
\end{abstract}


Keywords: Team learning, organizational culture, knowledge management, acquisition of knowledge, continuous improvement.

\section{Introduction}

In today's postindustrial society, knowledge has turned into a key source. However, organizations face numerous challenges in training and knowledge management. In today's era which is called knowledge era, organizations witness environments that get more dynamic and challenging day by day. Change and transformation is an inseparable part of today's world, in other words, the only constant part is change. Today, knowledge which is the intangible and spiritual capital is considered as an important and vital factor. In other words, the successful organizations against changes and transformations are the ones that can improve and develop their intangible and spiritual capital (Massa \&Testa, 2009). In information era, knowledge is the most important factor of long-term success for an individual and an organization. Because of its intangibility which makes it hard to be copied and imitated, today, knowledge is considered as an important resource for growth of organization (Mcelroy, 2003). In this regard, in a research titled "senior managers' understanding of knowledge management in Finland's vocational educational organization", Syysnummi and Laihonen (2014) found out that knowledge management is related to the process of value creation in organizations so that it should be considered as a basic part of modern educational organizations. Based on this subject, researchers state that more emphasis is needed on mastery of knowledge, which is related to educational tasks, and creation of empowerment of a knowledge structure supporting this task.

In fact, Druker (1993) believes that one of the reasons causing more efficient organizations and a basic key known in today's global economic environment is the knowledge of an organization (Zhao et al. 2012).

Knowledge management is a process through which organizations gain skills in the fields of learning (internalization of knowledge), coding of knowledge (externalization of knowledge), and distribution and transfer of knowledge (Malhotra, 2000). In this pattern, knowledge is organized into four fields which are:

Knowledge creation: it's the behaviors due to entering of new knowledge to human or social system, which provides a wide rangeincluding: discovery, acquisition, calling, and development; and it also has a close bind with innovation;Knowledge storage: all the activities leading to survival and maintenance of knowledge after entering to the system. The storage activity includes a variety of behaviors such as: activities due to knowledge credit, updating knowledge and etc. knowledge transfer: including a variety of behaviors such as: relationship, translation, interpretation, refinement, and presentation of knowledge; knowledge application: use of knowledge for decision-makings, performances, and achieving goals (Newman \& Conrad, 2000).

Therefore, knowledge management with creation and development of knowledge assets of an organization is related to the attitude of going beyond the objectives of knowledge. This 
requires systems to create and maintain the knowledge resources and to train and facilitate knowledge and organizational learning. In this regard, the organizations which consider knowledge as an asset and develop the values and organizational norms causing support of creation and sharing of knowledge are successful(Heidari, 2014). In a research titled "presenting a conceptual model of the impact of implementation of knowledge management on competitive advantage in small and medium enterprises", Ansari et al. (2013) found out that organizational culture and information technology have the most impact on success of knowledge management, and organizational structure has the least impact which can be because of lack of coherent organizational structure in Iran. In a research titled "the relationship between knowledge management and organizational innovation in an insurance company", Taleghani et al. (2013) found out that the indices of knowledge creation, knowledge storage, knowledge transfer, and knowledge application have a significant relationship with organizational innovation. Researchers also state that in order to achieve organizational innovation, managers need the integration of knowledge capitals and having knowledge of internal and external forces. On the other hand, knowledge must be distributed throughout the organization. Better distribution of knowledge increases the possibility of organizational innovation.

Scientific, cultural, and industrial development of the country and the standard improvement of them require the improvement of management in organizations. The improvement of management also requires awareness and proficiency with knowledge management. Today, management has had a great progress as a branch of human knowledge. Training and research in this field has become very widespread. Higher education systems have developed the education and research in the field of knowledge management in quality and quantity terms (Karmi \& Kouhbari, 2009). Schools are the most important centers of production and dissemination of knowledge. Creation of innovation and new knowledge, as a result, has been from the most important functions of educational institutions, and in this line, most of the efforts of the educational system have been in improvement of knowledge and intellectual capitals with enjoyment of the resources including teachers. In a research titled "study of the relationship between dimensions of knowledge management and the influencing key factors on it with employee's creativity", Shoghi et al (2012) found out that there is a significant relationship between employee's creativity with knowledge management, dimensions of knowledge management, knowledge organizes, knowledge distribution, and knowledge application and the key factors impacting on it (individuals, technology, culture and process).The findings also indicated that there is a significant relationship between the dimensions of knowledge management and the effective key factors on it.

Running a system of knowledge management in organizations is an organizational and collective action that everyone in different levels must be involved in. Organizational culture is what leads everyone in organization towards a specific goal spontaneously and seamlessly. Inan organization with current culture of knowledge management, excellent management in setting goals, policies, and even their behaviors and performances are specificallynoticed. Organizational culture, supporting knowledge, impacts on employees' attitude, behavior, and performance in a way that they would believe they can only be promoted in proportion to 
their positive performance in the process of knowledge management, and in this case, they can use the other cash benefits and welfare facilities. In fact, organizational knowledge is a necessity for successful knowledge management. Culture represents beliefs, values, norms, and social etiquette, and observes the individuals' behavior in organization. Generally, culture supports knowledge and encourages its values, sharing, and applications. The biggest challenges in attempts of knowledge management are in development of such cultures (Wong, 2005). In this regard, in a research titled "study of the impact of organizational culture on knowledge management (case study: Gilan's Office of Standards)", Khoramkhah et al. (2013) found out that there is a direct, significant, and positive relationship between organizational culture and knowledge management, and there is also a direct, significant, and positive relationship between the four features of organizational culture (involvement in job, compatibility, adaptability, and mission) and knowledge management, but the impact and the relationship of the compatibility feature with knowledge management is more and stronger. Therefore, the better implementation of knowledge management can be obtained by more support and development of features of organizational culture in organizations. Denison (2000) implies that organizational culture is the very basic values, beliefs, and ethics, which play an important role in an organizational management system. In his model,he describes the cultural features as follows: involvement in job, compatibility, adaptability, and mission. Brief dimensions are of the dimensions of organizational culture are: involvement in job: involvement in job means mental involvement in job, so the individual would work hardly usingtheir whole ability as Korean executive manager has stated in a company; compatibility (stability and integrity): the organizations with these features have different and strong culture and have the sufficient influence on employee's behavior; adaptability: the well-integrated organizations are hard to change. Therefore, the internal integration and the external adaptability can be considered as advantages of the organization mission. Successful organizations have a clear understanding of their goals and directions, so they define the organizational and strategic objectives and outline the visions of organization (Denison, 2000).

Therefore with proper management and organizational culture, the backgrounds of an effective application of knowledge should be provided. Therefore, organizations like educational systems that are responsible for education and training should try to use the knowledge in the organizations, so they can maintain the owners of knowledge or also the most important capitals of the organization in today's competitive world (Bidokhti et al. 2011). In this regard in a research titled "the relationship between organizational culture and knowledge management in Islamic Azad University of Sari and determination of the proportion of each component", Rezaie Kalantari et al. (2014) found out that there is a correlation between the two main variables of organizational culture and knowledge management, and there is also correlation between the components of organizational culture and knowledge management which are respectively organizational involvement, organizational flexibility, organizational mission, and organizational compatibility, and they indicated the regression equation of the share of the each component of organizational culture in knowledge management respectively 0.57 for organizationalflexibility, 0.5 for organizational mission, 0.4 for organizational compatibility, and 0.2 for 
organizationalinvolvement. Generally, the success of organizations in performing strategies including knowledge management depends on the support of organizational culture from the strategy. Organizations' efforts to become a knowledge-based organization will be successful if the required cultural features for performing knowledge management exist. Knowledge can be created and shared in an organization if it's supported by organizational culture (Sharifzade \& Boodlaie, 2008).

On the other hand, human is created sociable naturally, and their life is meaningless without cooperation and assistance.Theylearn many things in society. Team learning method is an approach that involves teachers in self-learning, self-responsibility, and effort. Today, the progressing society needs the responsible and self-sufficient individuals, and teaching the responsibility to learners at all levels requires an especial space in home, school, to university (Kazemi, 1996). Team learning is defined as a relatively permanent change in comprehensive level of team knowledge by the common experience of the team members. The set of behaviors and activities conducted by learner teams are divided into four dimensions: continuous improvement, improvement of communications, collaborative learning, and strategic leadership that improve the team development. We are going to have a brief definition of these dimensions: continuous improvement: refers to the range of team learning from the past experiences; improvement of communications: refers to improvement of dialogues and open communications due to open and honest relationships in a team; collaborative learning: refers to the team members who are knowledge sources of other team members; strategic leadership: the leader of team has an important role in improvement of team learning. In addition to the improvement of all the mentioned behaviors (continuous improvement, improvement of communications, and collaborative learning), the learning teams must have leaders who think about the development of the team members strategically and actively. For these leaders, learning is not something that just happens over time, but it's an issue that should be searched actively (Breso et al. (2008). In this regard in a research tilted "does the team stability have an intermediary role in in the relationship between leadership and team learning?"Savelsbergh et al. (2015) found out that both task-oriented and relationship-oriented leaderships had a positive and direct relationship with team learning. Team stability didn't have an intermediary role in the relationship between leadership and team learning, however, there was a direct and strong relationship between team stability and team learning. In a research titled "self-regulation learning, team learning, and project performance in entrepreneurship education" Harms (2015) found out that learning self-regulation has a positive relationship with evaluation at individual level, and team learning and psychological safety have a positive relationship with evaluation at the group level. In a research titled "the impact of group learning on educational attainment of fifth grade elementary school students in Pars Abad in 2011-2012 academic year", Pourfeizi (2012) also found out that group learning has an impact on interest; satisfaction, cooperation, and stress reduce of the students.

Knowledge management is an important issue, because it's related to the most important organizational capital which is the intellectual capital (Yaghoubi, 2006). Turning human capitals into organized intellectual assets, knowledge management creates value for 
organizations (Nikbakht et al. 2010; Yousefi, 2006). Today, absorbing knowledge elements and combining them together are important management challenges (Yaghoubi, 2006). Knowledge management is managing the scientific capitals as a process of social learning (Haji Karimi, 2006), it's creating a continuous integration between internal and environmental knowledge and in order to solve the problems, and it's also innovation in development of business (Beige, 2009).

Peter Senge states that team learning is a process through which the capacity of members is increased with desirable results. Teams would learn to learn from their experiences, to learn new approaches, and to publish their knowledge all over the organization quickly (King, 2001). In fact, if the team doesn't learn the organization won't learn, and the team learning is inevitable (Senge et al. 1999). In the study of knowledge management and organizational learning, combining knowledge management and learning has the goal of improvement of organizational efficiency with measuring the production amounts and profitability (Hovland, 2003).

Massingham states that: the strategic importance of learning capacity of organization and the role of sharing knowledge have specified the relationship between knowledge management and the learning capacity of organization (Massingham, 2009).

On the other hand, most of organizations use the knowledge to enhance the organizational agility. Therefore, development of a framework and a process for identification, acquisition, and dissemination of knowledge by a structured method in a compatible organizational culture is very important. Thereview of the past researches expresses the fact that organizational culture forms the behavior of employees and impacts on all the organizational aspects generally (Khoramkhah et al. 2013).

According to what is mentioned, in this research, we are seeking to answer this question that is there any relationship between team learning and organizational culture, and knowledge management of second grade high school teachersin Saveh city?

According to this question and the past researches, the following hypotheses were formulated:

1. There is a relationship between team learning and organizational culture,and knowledge management of second grade high school teachersin Saveh city.

2. There is a relationship between the components of team learning (continuous improvement, improvement of communications, collaborative learning, and strategic leadership) and knowledge management of second grade high school teachersin Saveh city.

3. There is a relationship between the components of organizational culture (involvement in job, compatibility, adaptability, and mission) and knowledge management of second grade high school teachersin Saveh city.

The conceptual model of the research is presented in the figure 1: 


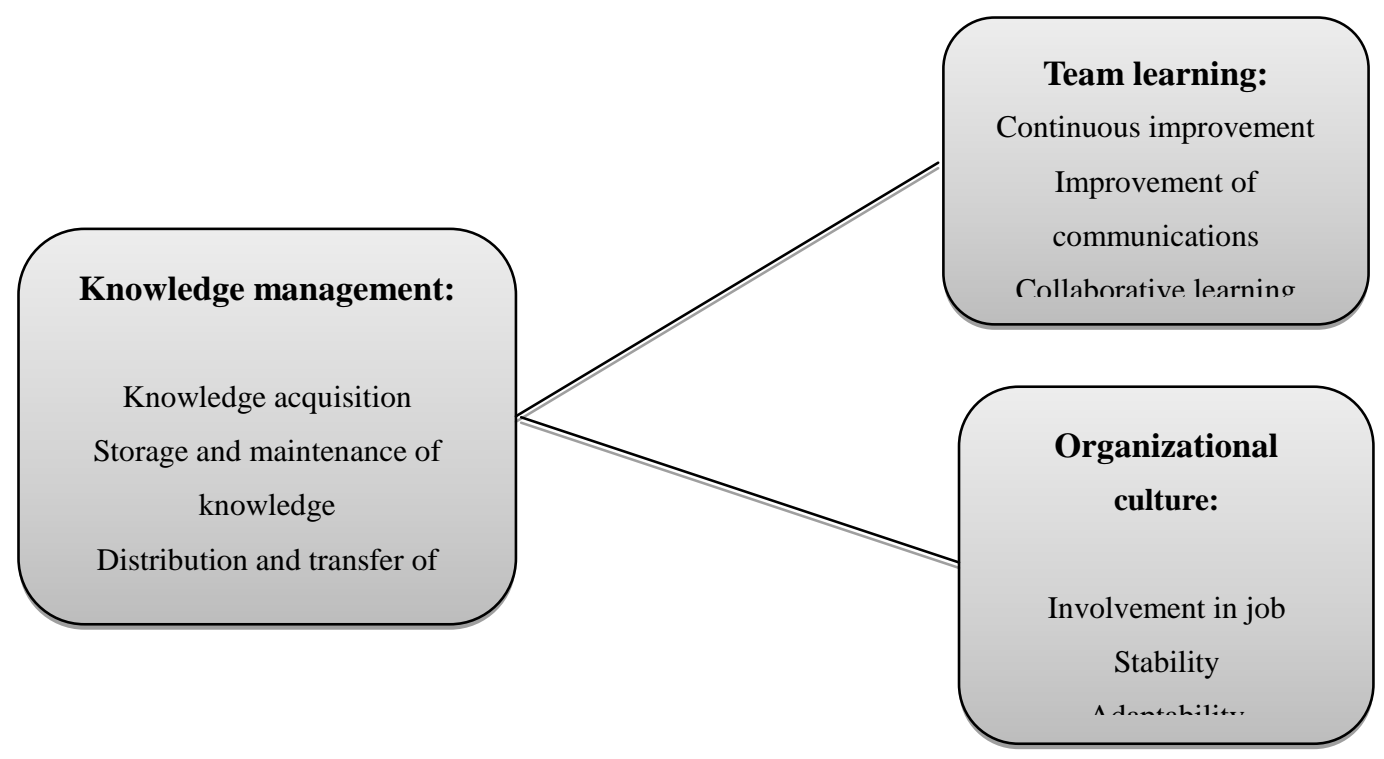

Fig 1. Conceptual model of the research (Breso et al. (2008); Denison, (2000); Fong \& Choi, (2009))

\section{Methodology}

The method used in this research was practical in terms of objectives and correlational-descriptive in terms of data collection method. In this research, the statistical population consisted of 160 individuals including all the second grade high school teachers in Saveh city. In this regard, 113 individuals (65 males and 4 females) were considered as a sample size using the Cochran formula and the Stratified random sampling method. In order to collect the data, three standard questionnaires of team learning of Breso et al. (2008), knowledge management of Fong \& Choi (2009), and organizational culture of Denison (2000) were used that the indices are presented in the table 1 . In order to assess the validity, the content validity was used, and the questionnaires were confirmed by the related experts, and in order to assess the reliability of the questionnaires, the Cronbach's alpha was used and the related coefficients were $0.84,0.82$, and 0.94 respectively for each of the questionnaires. The questionnaires were distributed among a group of second grade high school teachers in Saveh city and after receiving the questionnaires, the analyses were performed based on the descriptive and inferential statistics (Pearson correlation and multivariable regression). 
Table 1. Information due to variables and the Cronbach's alpha value of the research variables

\begin{tabular}{|c|c|c|c|c|}
\hline Main structures & Components of variable & Author & $\begin{array}{l}\text { Number of } \\
\text { questions }\end{array}$ & $\begin{array}{l}\text { Cronbach's } \\
\text { alpha }\end{array}$ \\
\hline \multirow{4}{*}{ Team learning } & Continuous improvement & \multirow{4}{*}{$\begin{array}{l}\text { Breso et al. } \\
(2008)\end{array}$} & $1-7$ & \multirow{4}{*}{0.84} \\
\hline & $\begin{array}{l}\text { Improvement } \quad \text { of } \\
\text { communications }\end{array}$ & & $8-12$ & \\
\hline & Collaborative learning & & $13-16$ & \\
\hline & Strategic leadership & & $17-20$ & \\
\hline \multirow{4}{*}{$\begin{array}{l}\text { Organizational } \\
\text { culture }\end{array}$} & Involvement in job & \multirow{4}{*}{$\begin{array}{l}\text { Denison } \\
(2000)\end{array}$} & $1-17$ & \multirow{4}{*}{0.81} \\
\hline & stability & & $18-31$ & \\
\hline & adaptability & & $32-45$ & \\
\hline & mission & & $46-60$ & \\
\hline \multirow{4}{*}{$\begin{array}{l}\text { Knowledge } \\
\text { management }\end{array}$} & Knowledge acquisition & \multirow{4}{*}{$\begin{array}{l}\text { Fong \& Choi } \\
\text { (2009) }\end{array}$} & $1-8$ & \multirow{4}{*}{0.94} \\
\hline & $\begin{array}{l}\text { Storage and maintenance } \\
\text { of knowledge }\end{array}$ & & $9-17$ & \\
\hline & $\begin{array}{l}\text { Distribution ad transfer of } \\
\text { knowledge }\end{array}$ & & $18-22$ & \\
\hline & Applying knowledge & & $23-25$ & \\
\hline
\end{tabular}

\section{Findings}


In order to review the normality of the data, the Kolmogorov-Smirnov test was used and the summary results are presented in the table 2 .

Table 2. Summary of the Kolmogorov-Smirnov test $(n=113)$

\begin{tabular}{|l|l|l|}
\hline Variables & Test statistics & Significance level \\
\hline Team learning & 0.95 & 0.32 \\
\hline Organizational culture & 0.75 & 0.63 \\
\hline Knowledge management & 0.89 & 0.41 \\
\hline
\end{tabular}

According to the table above, the significance level of all the variables of the research are higher than 0.05 . In other words, the data due to the variables of team learning, organizational culture, and knowledge management follow a normal distribution.

\section{Hypotheses test}

Main hypothesis: There is a relationship between team learning and organizational culture, and knowledge management of second grade high school teachersin Saveh city.

In order to study the relationship between team learning and organizational culture,and knowledge management, the multiple regression tests was used and the results are given in the table (3) and (4), and based on the assumptions such as: independence of the error terms, distribution diagram, and normality of the error term, the results were confirmed.

Table 3. Summary of the regression test in order to study team learning and organizational culture with knowledge management

\begin{tabular}{|c|c|c|c|c|c|}
\hline Model & $\begin{array}{l}\text { predictor } \\
\text { variables in } \\
\text { model }\end{array}$ & $\begin{array}{l}\text { Correlation } \\
\text { coefficient }\end{array}$ & $\begin{array}{l}\text { Square of } \\
\text { correlation } \\
\text { coefficient }\end{array}$ & $\begin{array}{l}\text { Adjusted } \\
\text { correlation }\end{array}$ & $\begin{array}{l}\text { Standard } \\
\text { error } \\
\text { estimate }\end{array}$ \\
\hline \multirow{3}{*}{1} & Team learning & \multirow{3}{*}{0.578} & \multirow{3}{*}{0.334} & \multirow{3}{*}{0.328} & \multirow{3}{*}{0.15254} \\
\hline & & & & & \\
\hline & $\begin{array}{l}\text { Organizational } \\
\text { culture }\end{array}$ & & & & \\
\hline
\end{tabular}

Criterion variable: knowledge management 
The information above indicates that the multiple correlation coefficients between the two components of team learning and organizational culture with knowledge management are estimated at 0.578 . In other words, these two variables almost explain 33.4 percent of variance of teachers' knowledge management $(\mathrm{R} 2=0.334)$.

Table 4. Team learning and organizational culture coefficients in prediction of knowledge management

\begin{tabular}{|l|l|l|l|l|l|}
\hline Model & B & SE & Beta & t & Significance level \\
\hline y-intercept & 1.033 & 0.189 & & 5.479 & 0.000 \\
\hline Team learning & 0.438 & 0.051 & 0.452 & 8.541 & 0.000 \\
\hline Organizational culture & 0.112 & 0.043 & 0.134 & 2.597 & 0.010 \\
\hline
\end{tabular}

The results of table above indicate that the constant and the constant and variable coefficient (intercept, team learning, and organizational culture) are significant at level of 0.05 . In other words in the regression model, y-intercept, team learning and organizational culture can predict the significance of changes of the teachers' knowledge management. Therefore according to the data in the table, the regression equation can be written as follows:

Predicted Knowledge management $(\mathrm{Y})=1.033+0.438$ (team learning) +0.112 (organizational culture)

Based on the regression equation above, it can be said that: adding one unit to the components of team learning and organizational culture, 0.438 and 0.112 unit will be added to the teachers' knowledge management.

First sub-hypothesis: There is a relationship between the components of team learning (continuous improvement, improvement of communications, collaborative learning, and strategic leadership) and knowledge management of second grade high school teachersin Saveh city.

In order to test the first sub-hypothesis, the Pearson correlation test was used between the components of team lessening and knowledge management and the results are indicate din the table 5:

Table 5. Correlation between the components of team learning (continuous improvement, 


\section{Macrothink}

improvement of communications, collaborative learning and strategic leadership)and knowledge management $(n=113)$

\begin{tabular}{|l|l|l|}
\hline Component & Correlation coefficient (r) & Level of significance (sig) \\
\hline Team learning & 0.584 & 0.003 \\
\hline Continuous improvement & 0.502 & 0.005 \\
\hline Improvement of communications & 0.586 & 0.007 \\
\hline Collaborative learning & 0.603 & 0.009 \\
\hline Strategic leadership & 0.572 & 0.004 \\
\hline
\end{tabular}

As indicated in the table above, the relationship between the components of team learning (continuous improvement, improvement of communications, collaborative learning, and strategic leadership) and knowledge management is significant at the level of 0.01 . Therefore, the null hypothesis can be rejected at the level of 0.01 and with a $99 \%$ confidence level, it can be concluded that there is a positive and significant relationship between the components of team learning (continuous improvement, improvement of communications, collaborative learning, and strategic leadership) and knowledge management of second grade high school teachers of Saveh city. In other words, increasing team learning and each of its components, knowledge management increases in second grade high school teachers of Saveh city.

Second sub-hypothesis: There is a relationship between the components of organizational culture (involvement in job, compatibility, adaptability, and mission) and knowledge management of second grade high school teachers of Saveh city.

Considering the normality of the both variables, the second sub-hypothesis was also tested by the Pearson correlation coefficient, and the summary of the calculations is presented in the table below:

Table 6. Correlation between the components of organizational culture (involvement in job, 
compatibility, adaptability, and mission) and knowledge management $(\mathrm{n}=113)$

\begin{tabular}{|l|l|l|}
\hline Component & Correlation coefficient (r) & Level of significance (sig) \\
\hline Organizational culture & 0.591 & 0.004 \\
\hline Involvement in job & 0.509 & 0.006 \\
\hline Compatibility & 0.593 & 0.008 \\
\hline Adaptability & 0.610 & 0.003 \\
\hline Mission & 0.579 & 0.005 \\
\hline
\end{tabular}

As indicated in the table above, the relationship between the components of organizational culture (involvement in job, compatibility, adaptability, and mission) and knowledge management is significant at the level of 0.01 . Therefore, the null hypothesis can be rejected at the level of 0.01 and with a $99 \%$ confidence level, it can be concluded that there is a positive and significant relationship between the components of organizational (involvement in job, compatibility, adaptability, and mission) and knowledge management of second grade high school teachers of Saveh city. In other words, increasing organizational culture and each of its components, knowledge management increases in second grade high school teachers of Saveh city.

\section{Conclusion}

The most fundamental characteristic of intelligent organizations in the 21 st century is the emphasis on knowledge and information. Knowledge is a powerful tool that can make changes in the world and can make the innovation possible. Today in the era of rapid progress of knowledge and technology that the face of schools is totally changing, the enjoyment of the teachers from knowledge, information, techniques, principles, and educational strategies is not enough, but organizing and correct use of information are necessary in educational environments (Rahimi \& Najafi, 2007). Scientifically, knowledge and training management are fundamentals of growth of software movement and producing knowledge in schools in the century of information. The management that begins organizing, retrieval, transfer, and dissemination of knowledge in schools, uses the students' intellectual capitals with creation of strategic motivation in them, and speeds up the cycle of knowledge which establishes the organizational learning basis (Karamipur, 2003, cited in Shoghi \& Khoshghiam, 2012). Therefore considering the importance of the subject, this research studied the relationship between team learning and organizational culture, and knowledge management of the second grade high school teachersin Saveh city, and based on the hypotheses, we are going to discuss the conclusions as follows:

The main hypothesis indicated that there is a relationship between team learning and organizational culture, and knowledge management in the second grade high school 
teachersin Saveh city. It can be said in explanation of this hypothesis that knowledge is the most important factors of long-term success for organization in information era. Because of its intangibility which makes it hard to be copied and imitated, today, knowledge is considered as an important resource for growth of organization. The management of this strategic factor is defined as "exploiting and development of knowledge assets of an organization in order to achieve its objectives". One of the basic objectives of knowledge management is empowering and transferring knowledge among the organizational entities including individuals, associations, and units. The acquisition and creation of knowledge through the process of organizational learning is one the vital factors in knowledge management effectiveness. Learning is a relatively permanent change which is a result of direct or indirect experiences. The basic implementation of this definition includes learning along with changing in behavior.This change is a permanent change, it should finally be noticed that learning is a gradual process, and it won't happen at once. It should be noticed that learning can happen in team and in a more effective way. Collaborative is based on reaching censuses through collaboration between the group members, and it's against competition. In competitive learning, individuals try to act better than others or try to defeat them, while in team learning which is a learner-based method, the learners try to achieve a common objective through collaboration, so that learning is not only a teaching technique but also a special educational strategy. The positive implications of team learning can help the team members' commitment for more attempts and solving complicated problems that even the most talented memberscan't solve. As mentioned in the second chapter, Senge believes that team learning is vital, because the teams form the basis of learning in modern organizations, and as long as the teams don't learn, the organizations won't be able to learn. Team learning changes the passive role of learners in traditional approaches to an active element in the learning process. In this method, individuals learn from the experiences of other members of teams. Finneran (1999; cited in Shoghi \& Nazari, 2012) believes that an appropriate culture is one of the basic infrastructures for success of knowledge management in organizations. Organizational culture impacts on all aspects of organization, because as the studies indicate, culture impacts on setting objectives and strategies, individuals behavior and organizational performance, motivation and job satisfaction, creativity and innovation, decisions and amount of employees' collaboration in affairs, amount of sacrifice and commitment, hardworking, anxiety level and etc. researches also indicate that excellent and successful organizations have strong and effective culture. As some of researchers stated about the importance of organizational culture, any kind of change in organization is impossible regardless of organizational culture. If the artifacts and apparent effects, values and norms, assumptions and fundamental organizational beliefs are cooperated with the culture of learning, the organization moves towards development and growth. The employees in these organizations permanently try to learn and improve their personal and team knowledge, and subsequently the individual, team, and organizational knowledge resources will develop, and this approach can change to a sustainable competitive advantage for organizations. These results are consistent with the research results of Babnika et al. (2014) Van der Harr et al. (2013), Azma \& Mostafapour (2011), King (2009), Rezaie Kalantari et al. (2014), Akhavan et al. (2012), Ghorbanizadeh et al. (2011), and Amin Bidokhti et al. (2011). 


\section{Mll Macrothink}

Journal of Sociological Research

ISSN 1948-5468

2015, Vol. 6, No. 2

The first sub-hypothesis indicated that there is a relationship between the components of team learning (continuous improvement, improvement of communications, collaborative learning, and strategic leadership) and knowledge management of second grade high school teachersin Saveh city. In explanation of this hypothesis, it can be said that team learning has four components of continuous learning, improvement of communication, collaborative learning, and strategic learning. Continuous learning refers to learning from the past experiences, while knowledge is a combination of experiences, values, information, and systematic peer reviewed attitudes that make a framework for evaluation and enjoyment of new experiences and information. Every organization has the two types of explicit and tacit knowledge. Explicit knowledge is the knowledge understood in writing and speech forms, and tacit knowledge is the knowledge that individuals are usually able to do, but unable to describing or state. The tacit knowledge hasn't been considered enough so far. Organizations must be aware of the benefits of the both types of knowledge and must collect and protect them in different ways. Team learning provides a situation for employees to share their experiences with other members of team. In this way, the long-term interactions of tacit knowledge are shared between the team members. Collaboration is defined as the process of creation and protection of a common understanding from tasks or problems, distribution of responsibilities among team members, and sharing expertise among them, in which the mutual cognition is made and negotiated.In this attitude, a successful collaboration requires improvement of mutual cognition. In fact, the basis of contribution in team behaviors is the relationships between the team members. In fact, the existence of open Relationships is based on the reliance originating from mutual honesty. Improvement of communications refers to open and honest relationships of team members, which is related to knowledge management.

Collaborative learning refers to the team members being considered as knowledge resources of others. Each member of a team has experiences which are gradually obtained from past times. These individual knowledge resources are important for performance of team. In other words, this component of team learning has greater relationship with knowledge management.

The last component of team learning emphasizes on the important responsibility of team leader in improvement of team learning. In addition to improvement of all of the mentioned behaviors (continuous improvement, improvement of communications, and collaborative learning), the learning teams must have leaders who strategically and actively think about development of their members. The team leader coordinates the members' activities and leads the team to achieve the goals. They should use the conflicts among the team to make effective decisions and to manage the emotional conflicts, and these factors cause the use of other processes of team learning which facilitates the relationship between team learning and knowledge management. The results are consistent with the research results of Savelsbergh et al. (2015), Babnika et al. (2014), Azma \& Mostafapour (2011), King (2009), Keyvanara et al. (2011), Ghorbanizadeh et al. (2011), and Amin Bidokhti et al (2011).

The second sub-hypothesis indicated that there is a relationship between organizational culture components (involvement in job, compatibility, adaptability, and mission) and knowledge management of the second grade high school teachersin Saveh city. In 
explanation of this hypothesis it can be said that involvement in job includes delegation of authority, innovation, and ability to manage their work, valuing group works for common goals, and development of employees' skills. In fact when an organization tends to improve the skills of its employees, it improves the knowledge resources of the organization, and it happens by transferring and sharing the knowledge. The employees who have the required skills for doing their duties can help the organization to achieve its goals. Organizations would have a better performance by creating teams, because teams are formed of skillful members who have authorities to do the jobs, and it causes the achievement of goals and attitudes of the organization.

Compatibility happens in effective, stable, and consistent organizations, and the employees' behaviors originate from fundamental values. Leaders and subordinates are skillful at reaching an agreement (even when they have opponent attitudes) and organizational activities are collaborated and consolidated as well. The organizations with these characteristics have a strong and different culture and impact the employees' behaviors. In such organizations, employees have high communicational abilities, and conflicts are used for better performance and more efficient decisions. In such organizations, employees' knowledge is used to achieve the organization goals, and the result is effectiveness and achievement of the organizational goals.

Adaptability is rarely changed in organizations with high integrity. Therefore, internal integrity and external adaptability can be considered as a benefit and a superiority of organizations. Compatible organizations are led by customers. They risk, heed their mistakes, and have the experience of making changes. They are continuously improving the ability of organization to value the customers. In fact, adaptability is not possible without understanding the environmental changes. Environmental changes are usually accompanied with some lack of reliability. To manage this lack of reliability, organizations try to make a learning organization to obtain experiences from the important problems impacting the future of the organization, and to keep them as the knowledge resource in the organization. This method would reduce the environmental unreliability and would help the organization to achieve the preset goals.

It can be said that the main feature of organizational culture is mission. The organizations which don't know where they are and what their present status is usually go to astray. Successful organizations have a clear comprehension of their goals so that they define the organizational and strategic goals and outline the organization vision. According to one of the definitions presented in the second chapter, knowledge management refers to"exploitation and development of knowledge assets of an organization in order to achieve its goals". In better words, knowledge management can be considered as a strategy to achieve the mission of organization which happens based on organizational knowledge and non-organizational knowledge if needed. The results are consistent with the research results of Van der Harr et al. (2013), Rezai Kalantariet al. (2014), Nasiripour et al. (2013), Khoramkhah et al. (2013), and Akhavan et al. (2012).

According to the research findings, the following suggestions are made: 


\section{Macrothink}

Journal of Sociological Research

ISSN 1948-5468

2015, Vol. 6, No. 2

1. To recognize special cultural factors which are exclusive for every organization and can become an improvement or an obstacle for implementation of knowledge management.

2. To use employees' personal experiences to value their suggestions and to use their resources, causing reduce of costs and increase of employees' commitment.

3. To create sympathetic teams causing the improvement of learning levels of organizations.

4. To value the group works in organization and to delegate authorities that is necessary to improve the level of collaboration in work (involvement in job).

5. To emphasize on fundamental values, agreements, and collaboration and coherence in organization that is necessary to achieve compatibility in organizations.

6. It is suggested to researchers to continue this research to achieve an appropriate model with more variables and dimensions.

\section{References}

1. Akhavan, P., Sanjaghi, M.E. and Ojaghi, H. (2012). Study of the relationship between innovative management, organizational culture and knowledge management (case study: selected industrial-research organizational), Journal of Defense Strategies, 10(38), pp. 175-199.

2. Amin Bidokhti, A.A., Makvand Hoseini, Sh. And Ehsani, Z. (2011). Study of the relationship between organizational culture and knowledge management in department of education in Semnan, Journal of Strategy, 20(59), pp. 191-216.

3. Ansari, M., Rahmani, H., Rahmani, K., Pasbani, M. and Asgari, M.A. (2013). Presenting a conceptual model of the impact of implementation of knowledge management on competitive advantage in Small and Medium Enterprises (SMEs), Journal of Business Management, 5(1), pp. 21-40.

4. Babnika, Katarina; Trunk Širca, Nada and Dermol, Valerij. (2014). Individuals learning in work teams: Support to knowledge management initiatives and an important source of organizational learning. Procedia - Social and Behavioral Sciences 124, pp. $178-185$.

5. Beige M. Knowledge management to achieve organizational learner. Monthly Vehicle Engineering and Related Industries 2009; 1(3):33-40. [Persian].

6. Bresó, I., Gracia, F., Latorre, F., \& Peiró, J. (2008). Development and validation of the Team Learning Questionnaire. Comport. Organ. Gest. v.14 n.2 Lisboa out, pp. 145-161.

7. Denison, D. R. (2000). "Organizational culture: Can it be a key lever for driving 


\section{Ml Macrothink}

Journal of Sociological Research

ISSN 1948-5468

2015, Vol. 6, No. 2

organizational change". In S. Cartwright \& C. Cooper (Eds.), the $\mathrm{h} \&$ book of organizational culture. London: John Wiley \& Sons.

8. Ellis, A. P., Hollenbeck, J. R., Ilgen, D. R., Porter, C. O., West, B. J., \& Moon, H. (2003). Team learning: CollectivelyConnecting the Dots. Journal of Applied Psychology, 88 (5), 821-835.

9. Fong, S.W.P and Choi, K.Y.S. (2009). The Processes of knowledge management in professional services firms in the construction industry: a critical assessment of both theory and practice. Journal of knowledge management, 13(2), pp. 110-126.

10. Ghorbanizadeh, V., Hourmanesh, F. and Gholamhoseini, H. (2011). The role of learning culture and knowledge management in organizational agility, Journal of Studies in management, improvement and evolution, 21(65), pp. 47-72.

11. Hajikarimi M.H. (2009). Study and analysis of knowledge management in construction industry in terms of advantages and limitations, International Journal of Civil Engineering, p. 60.

12. Harms, R. (2015). Self-regulated learning, team learning and project performance in entrepreneurship education: Learning in a lean startup environment. Technological Forecasting and Social Change.

13. Heidari, H.R. (2014). Study of the relationship between intellectual capital and knowledge management among the employees of Melli bank in Saveh, MA Thesis in governmental management, Faculty of Human Sciences, Islamic Azad University of Saveh.

14. Hovland, Ingie. (2003).Knowledge Management and Organizational Learning: An International Development Perspective. Overseas Development Institute.

15. Karimi, R. and Kouhbari, F. (2009). Knowledge management in courses of universities in Iran and selected universities. Proceedings of the National Conference, Tehran: Ketabdar Press.

16. Kazemi, N. (1996). Learning and Accountability, Journal of Education, Issue 110, pp. 104-107.

17. Keyvanara, M, Yazdkhasti, A., Bahrami, S. and Mas'udian, Y. (2011). The relationship between knowledge management and organizational intelligence in Isfahan University of Medical Sciences, Journal of Health Information Management, 8(5), pp. 673-680.

18. Khoramkhah, H., Hashemnia, Sh. And Peiman, S.J. (2013). Study of the impact of organizational culture on knowledge management (case study: Gilan's Office of Standards), Journal of Cultural Management, 7(19), pp. 13-24.

19. King, W. R. (2009). "Knowledge Management and Organizational Learning", Annals of Information Systems, Vol. 4. DOI 10.1007/978-1-4419-0011-1_1.

20. King, W. R. 2001. Strategies for creating a learning organization. Information 


\section{I Macrothink}

Systems Management, winter 2001, pp. 12-21.

21. Malhotra, Yogesh (2000), From Information Management to Knowledge Management: Beyond the "Hi-Tech Hidebound" Systems. In K. Srikantaiah \& M.E.D. Koenig (Eds.), Knowledge Management for the Information Professional. Medford, N.J.: Information Today Inc. Available at: http://www.brint.org/IMtoKM.pdf.

22. Massa, S; Testa, S. (2009). "A knowledge management approach to organizational competitive advantage: Evidence from the food sector", European Management Journal, Vol. 27, pp. 129-141.

23. Massingham, Peter. (2009).Organizational commitment, knowledge management interventions, and learning organization capacity, The Learning Organization journal.2009; 16(2): pp. 122-142.

24. McElroy, M. W. (2003). "The New Knowledge Management: Complexity, Learning, and Sustainable Innovation", Butterworth-Heinemann, Boston.

25. Nasiripour, A.A, Reisie, P., Mas'udi Asl, I. and Nazari, A. (2013). The relationship between organizational culture and intellectual capital in Imam Khomeini Relief Committee, Journal of Health, 7(1), pp. 80-90.

26. Newman, B. B; Conrad, K. W. (2000). "A Framework for Characterizing Knowledge Management Methods, Practice, and Technologies, in: Proceedings of the Practical Aspects of Knowledge Management", (PAKM 2000), The Knowledge Management Forum, Basel, Switzerland, 2000, pp. 16-33.

27. Nikbakht A, Siadat S, Hoveida R, Moghadam A. Study of the Relationship between Knowledge Management and Chairpersons Leadership Styles at Isfahan University of Medical Sciences from Faculty View Points. Health Information Management 2010; 7(2): p.224.

28. Pourfeizi, I. (2012). Impact of group learning on educational attainment of fifth grade elementary school students in Pars Abad in 2011-2012 academic year, MA Thesis, Islamic Azad University of Ardabil.

29. Rahimi, H. and Najafi, M. (2007). Knowledge management in educational organizations. Tehran: Javedane Press.

30. Rezaie Kalantari, M., Salehi, M. and Taheri, S.M. (2014). The relationship between organizational culture and knowledge management in Islamic Azad University of Sari and determination of the proportion of each component, Journal of New Approach in Educational administration, 5(1), pp. 175-188.

31. Savelsbergh, C. M., Poell, R. F., \& van der Heijden, B. I. (2015). Does team stability mediate the relationship between leadership and team learning? An empirical study among Dutch project teams. International journal of project management, 33(2), pp. 406-418. 
32. Senge, P.M, etal. The Dance of change: The challenges of Sustaining Momentum in Learning Organizations. New York: Doubleday, 1999.

33. Sharifzade, f. and Boodlaie, H. (2008). Knowledge management in service, manufacturing and administrative organizations. Tehran: Jahad Daneshgahi Press.

34. Shoghi, B. and Khoshghiam, Z. (2012). Knowledge management and organizational learning (concepts, definitions and theories). Tehran: Shamim Danesh Press.

35. Shoghi, B. and Nazari, Z. (2012). Organizational learning and organizational culture (concepts, definitions and theories). Tehran: Raz Nahan Press.

36. Shoghi, B., Hoseinzadeh, D. and Molaie, A. (2012). Study of the relationship between the dimensions of knowledge management and key factors affecting it and employees' creativity (case study: Karizan Khodro Co. in Kaveh industrial city). The first national conference on accounting and management, Islamic Azad University of Nour.

37. Sysnummi, Pirjo. and Laihonen, Harri. (2014). Top management's perception of knowledge management in a vocational education and training organization in Finland", International Journal of Educational Management, Vol. 28 Issue 1, pp. 53-65.

38. Taleghani, Gh.R., Anvari, A. and Eftekhari, L. (2012). Relationship between knowledge management and organizational innovation in an insurance company. Journal of Researches in Insurance, 27(1), pp. 151-171.

39. Van der Haar, Selma; Segers, Mien and Jehn, Karen A. (2013). Towards a contextualized model of team learning processes and outcomes. Educational Research Review, 10, pp.1-12.

40. Wong, K.Y, (2005). Critical Success Factor for Implementing Knowledge Management in Small and Medium Enterprises, Industrial Management \& Data System, Vol. 105, Issue 3.

41. Yaghoubi M. KM ring lost in health Organization, 5th annual Congress of Student of Health Services administration. Tabriz.9-12 April 2006: p. 355.

42. Yousefi AR. (2007). Evaluation factors of knowledge management in selected teaching hospitals in Isfahan. [BS Thesis]. Health Management and Economics Research Centre. Isfahan University of Medical Sciences.

43. Zhao, J; Depablos, P. O; Oi, Z. (2012). Enterprise knowledge management model based on China's practice and case study. Computers in Human Behavior, Vol. 28, pp. 324-330. 